\title{
ADOPTING JAPANESE LEAN PRACTICES INTO THE VIETNAMESE CONTEXT: SLOW AND STEADY IS THE SURE WAY TO GO
}

\author{
Reynold James, Phd. MBA, Academic Staff, Swinburne University of Technology \\ Anh Dinh Nhu, MB (HRM), Lecturer, Hoa Sen University
}

\begin{abstract}
In tandem with Vietnam's growing economic activity in recent years is the observable trend of Vietnamese firms across various sectors increasingly adopting Japanese lean management principles and practices. Evidencing this is the ever increasing extent of lean related activity in the form of lean management and production workshops, seminars, and training and consulting activity across the nation, with the year 2013 -christened by some- as the 'year of the lean concepts'. Whilst lean has its advantages, and with a coterie of scholars advocating that lean is an epoch making model, transferable like a technical object from any one geographic location into another and is devoid of context, there are others who advocate that the efficacy of lean -when transplanted outside of Japan- is contingent upon several contextual factors within the host nation. The extant literature on lean and on institutional transplantation reveals several cases wherein attempts to transplant the lean model into non-Japanese socio-cultural climes have resulted in outcomes ranging from minimal success to failure. This paper highlights a few contextual aspects that merit consideration by Vietnamese industries adopting lean practices, and in so doing, purports to tone down any unrealistic perceptions that managers and industrialists may harbor, about lean being a silver bullet that can overnight transform their firms into star performers.
\end{abstract}

Keywords: lean, transplantation, Toyota Production System (TPS), Kaizen

\section{INTRODUCTION}

The academic literature on the transplantation of Japanese lean production and management practices into Vietnam's context is rather scant. Review of this literature however, coupled with an examination of the relatively greater amount of information from other sources including the popular press, professional media, and the several online sources eulogizing the lean model, seem indicative of two things, namely : (i) hectic lean related activity is underway in Vietnam, in terms of the growing awareness of the lean model, training / consulting activity in the discipline, and therefore, seemingly a greater inclination towards adoption of lean; and (ii) there is neither any serious mention of the critical role played by various environmental, socio-cultural and human (ie contextual) factors that are 'lean enabling', nor any exhaustive study addressing the extent of presence or absence of such factors within Vietnam, that determine the possible efficaciousness of a model transplanted from its original environs (Japan) into the host country. The apparent disregard for this latter point, whether through design or ignorance of 
-seemingly several- of those involved with implementing the lean model into Vietnam, could possibly result in the over estimation of the power of lean to deliver results.

Significance and Sequence: Given the frenetic 'lean adoption' activity currently underway in Vietnamese industry, we consider our study as being highly relevant and timely for industry practitioners and entrepreneurs, to aid their understanding of various forces intrinsic to cross-border lean transplantation scenarios, resulting in a more realistic outlook towards what might be achieved from the transplanted model. It is worth mentioning that on the other hand however, it is often not in the interests of consultants, trainers and their ilk, as they need to make a living, to highlight various impediments that hinder the adoption of a pure form of lean into non-Japanese environmental scenarios.

Our paper initially reviews the literature on lean, the associated literature on the transfer of Japanese management techniques and lean production from Japan to other nations, and then describes the historical and contextual factors that facilitated the emergence of the model in the first place. Following this is a description of the main constituents comprising the lean system. We next briefly examine situations wherein attempts to adopt lean into contextual settings outside of Japan yielded less than satisfactory outcomes. In so doing, extensive reference is made to the attempts of Toyota Motor Corporation (TMC) Japan transplanting its lean production system (TPS), into one of its overseas affiliates with a context somewhat similar to Vietnam, but dis-similar to Japan. This is followed by a comparison between the broad lean related contextual conditions observable in their presence or otherwise within Vietnam, on the one hand, and the lean enabling conditions (within Japan) on the other. Based on this comparison, and also the lessons learned from the other transplantation attempt discussed earlier, we highlight a few broad factors for consideration by industry practitioners, regarding the possible outcomes for the lean model being transplanted into Vietnam.

\section{Literature Review}

The considerable literature on the transfer of Japanese management techniques and lean production from Japan to other nations mainly addresses the more developed countries such as the USA and Europe (Berggren, 1994; Besser, 1996). Relatively less extensively analysed (with a few exceptions such as BeckerRitterspach, 2009; James 2011a; Anh, Jing \& Matsui, 2011; Phan Chi Anh and Nguyen Dang Minh, 2012 etc), is the transfer to developing countries including China, India and Vietnam. Given the growing importance being accorded to developing economies in Asia, and also with the $21^{\text {st }}$ century being labeled 'the Asian Century' by nations such as Australia this is a gap which requires filling in.

Lean production as a term first surfaced in 1990, in the book 'The Machine that changed the World' (Womack et al., 1990), which enhanced the popularity of the lean concept outside of Japan. However, the manufacturing concept of just-in-time (JIT) had been known over a decade earlier, and the technical aspects of lean production widely discussed. According to the book:

'Lean production is 'lean' because it uses less of everything compared with mass production - half the human effort in the factory, half the manufacturing space, half the investment in tools, half the engineering hours, to develop a new product in half the time. Also, it requires keeping far less than half the needed 
inventory on site, results in many fewer defects, and produces a greater and evergrowing variety of products." (Womack et al., 1990, p.13)

Forrester (1995) describes 'lean' as a holistic process of waste reduction comprising a number of interdependent elements. Liker and Hoseus (2010) differentiate the lean model from mass production, based on lean's singleminded focus on eliminating waste in all aspects of the enterprise. An enterprise exists to add value to customers through a series of activities that transform inputs into outputs and anything other than the minimum needed to perform that valueadded function is waste. The driving force behind lean production is a constant quest to eliminate waste. Anything that does not produce value can be classified as waste. Described as the architect of the Toyota Production System (TPS), the forerunner of lean, Ohno (1988) attributes waste to seven sources, namely: over-production, inventory, waiting, processing, motion, conveyancing, and correcting. Waste reduction in lean production systems is facilitated through the combined use of a rash of tools and techniques.

Several others (e.g. Preece and Jones, 2010; Worley and Doolen, 2006; Oliver, Delbridge , and Lowe 1996; Karlsson and Ahlstrom,1996; and Forrester, 1995) support the foregoing, and comprehensively summarize the key constituents of the lean model as being comprised of the following elements: $5 \mathrm{~S}$ (sort, straighten, shine, standardize, and sustain); customer pull production system; Kaizen - continuous improvement; just-intime production (JIT); Kanban ; minimal inventories; quick changeovers; value stream mapping; small lot production; quick set-up times; standardized work; Takt time; production leveling; total preventative maintenance; visual control systems; zero defects; right-first-time; Andon cord; general purpose machines; greater product variety; and more niche and customized products.

Critical to our paper are the arguments of these scholars, that unlike more traditional work systems, a successful adoption of the lean system involves a major change in direction, across many, or even all other organizational sub functions. For example, HR-related developments under lean production include : integration of conception and execution of tasks within flexible cell-based production areas; devolved responsibilities and empowerment to multifunctional team-based direct workers on the workshop floor; fewer functional specialists; investment in the development of people; continuous improvement and learning processes through quality circles and suggestion schemes; group-based problem identification, resolution, and implementation; more lateral communication across functional boundaries; multi-directional information systems; high trust; high commitment and sense of obligation to the company etc.

The literature on lean reveals two interpretations of the concept. The first, which is popular amongst consultants, managers and engineers etc, and also popular apologist vein writers (e.g.Liker and Hoseus, 2008) who claim that Lean production, is an efficient, humanisticmachine. The second interpretation describes Lean as a very sophisticated prison, and is popular among critical theorists (see Parker and Slaughter, 1988, 1994). Commonly underscoring both viewpoints however, is the view supported by a strong body of literature, that the 'Lean' model is transferable like a technical object ie from one cultural base to another, without a supportive environment ,eg, Japan to USA (Womack 
et al, 1990;Florida and Kenney 1991;Pil and MacDuffie,1999; Pardi, 2005). Insufficiently addressed, and considered irrelevant, are critical aspects including the contextual setting, socio-cultural, environment and historical trajectories.

Recent literature however, has increasingly concerned itself with the relatedness between contextual (including socio-cultural) differences and transfer outcomes of various lean production practices, with concepts such as 'hybridisation', 'third culture' and 'recontextualization' etc gaining ground (Westney, 1999; Wilms, Hardcastel and Zell, 1994). Emphasising the criticality of the context within which transfers occur, are Cooney and Sewell (2000), who question the popular perception of lean as being a monolithic, epoch-making production model, while claiming that wide variations exist between the methods used and the extent of implementation of the same. They argue there is a clear consonance between how lean production is implemented, and the context surrounding it. Others (e.g. Jones and Liu, 2005; Womack and Jones, 1996; Sugimore et al 1997) argue that culture is central to lean as a system and its successful deployment, and that lean was initially developed within the strict confines of Japanese contextual conditions and institutions. According to Gough \& Fastenau (2003), Japanese manufacturers who pioneered lean production are now under increasing pressure to modify their production processes and staff management systems within Japan itself, to respond to significantly different economic and social conditions. Also, there is no one lean system, but rather, several variants of the model. According to these authors, Nissan and Toyota have different interpretations of continuous improvement (Kaizen).

Through this paper we hope to contribute to the existing literature on the relatedness between contextual (including socio-cultural) differences and transfer outcomes of the lean model, as applicable to the scenario within Vietnam.

\section{Methodology}

A qualitative methodology has been adopted in this study, since this paper mainly examines the twin questions of 'what' and 'how' of the topic being studied (Wertz et al.,2011:2), and seeks to understand the contextual and sociocultural aspects involved within cross border / cross cultural transplantation of the Japanese institution of lean, within the natural settings of Vietnam, over a period of time. Within the context of a qualitative methodology, our paper strongly identifies with an exploratory research approach, since we ask the question 'what is going on here' (Schutt,2006); since our data collection relies mainly on secondary research; and also since this research is being conducted into an issue or problem where there are very few or no earlier studies to refer to, owing to which the focus is on gaining insights and familiarity for deeper, more focused later investigations. The paper therefore, rather than constituting an empirical study, sets the stage for deeper, more empirically focused subsequent analyses of the area being researched.

This research is based on an extensive review of the literature on lean. Content analysis (Holsti,1969,p.14) was initially carried out to assess whether journal articles and other (non academic literature) reviewed, broadly addressed perspectives and theories linked to the lean concept, and aspects relevant to the socio-cultural relatedness of lean; and also if answers were broadly available to the key questions required to satisfy requirements of content analysis (see Krippendorff,1980). Categorization and 
subsequent a priori coding processes were undertaken, to allow for exclusivity and exhaustiveness. The Content analysis placed particular emphasis on the ideal environmental factors, national and work culture within Japan that are 'lean enabling'. The paper first isolates from the literature, a few environmental and sociocultural aspects within the context of Japan that constitutes the ideal breeding grounds for lean. It next attempts to link these lean enabling factors with a few dimensions of Geert Hofstede's 5-D model. Dimensions of this model that most seem to describe the Japanese (lean enabling) national cultural / organizational behavior context are then compared to the Vietnamese national cultural / organizational behavior context, to check for the extent of consonance between the latter, and the ideal 'lean enabling' environment. The variation observable between Japan's and Vietnam's scores on the two chosen dimensions, are deemed as an indicative measure, of the level of success Vietnam could expect, from any lean adoption initiatives. To support this line of reasoning, a further comparison is made, between the scores and context of Vietnam, and another nation, whose scores and context are fairly similar to Vietnam (namely India). Based on the foregoing comparative analyses, a few conclusions are arrived at, based on the broad reasoning that the outcomes achieved by a large Japanese corporation attempting to transplant its lean model into the Indian context, are possibly similar to the outcomes that may be expected in Vietnam.

\section{The Environmental and Socio- Cultural Context of Lean}

Assuming that lean is simply a set of concepts, techniques, and methods that can be implemented by managerial dictates or policy changes, would be a mistake. An important feature of TPS (from which flows lean) is that it was developed in response to the unique environmental and socio-cultural factors faced by Japan. The most distinctive factor was the lack of natural resources, with the drive to minimize waste in every form being an important ingredient of lean thinking. Gough \& Fastenau (2003) further extend this argument in stating that lean systems rather than being some form of universal "best practice", are in fact responses to a unique set of environmental conditions at a particular time in the industrial and societal history of Japan. Constrained natural resources and socio-cultural factors have had a significant influence on the values, beliefs, and behaviors of the Japanese workforce. Therefore replication of particular production and labor processes associated with the lean model without similar attendant environmental factors are unlikely to produce the significant competitive advantages enjoyed by the originators.

The second most distinctive feature is, that daily living in the Japanese context tending to be centered around a cultural pre-occupation with work (something which significantly differs from Vietnamese culture). This seems to be well borne out by Robbins (1996), who claims that national culture continues to be a powerful force explaining a large proportion of organizational behavior.

Seemingly corroborating this latter point, and perhaps explaining the congruence between Japanese national culture and lean, are the scores assigned to Japan by Hofstede (2011) on dimensions of masculinity (95), and for uncertainty avoidance (92), making Japan one of the most masculine and uncertainty avoiding societies in the world. High masculinity within a society indicates its being driven by competition, achievement and success, with success being defined by 
the winner / the best in field - a value system that starts in school and continues throughout organizational behavior (See Vietnamica,2012). The fundamental issue here is what motivates people, wanting to be the best (masculinity).Uncertainty avoidance on the other hand, describes the extent to which the members of a culture feel threatened by ambiguous or unknown situations and have created beliefs and institutions that try to avoid such situations.

An expression of Japan's masculinity is their notoriety for workaholism, their masculine norm of hard and long working hours, their drive for excellence and perfection in almost every sphere of life, with examples being, their material production (monodukuri), their services related activities (hotels, restaurantsand presentation -gift wrapping and food presentation etc.) Their masculinity also translates into employees in corporate Japan being most motivated when they are fighting in a winning team against their competitors. In like vein, Japan's high uncertainty avoidance manifests itself in their great attention towards preparing themselves for any uncertain situation, which goes beyond emergency plans and precautions for sudden natural disasters but also for every other routinized aspect of society. Everything done is prescribed for maximum predictability. From cradle to grave, life is highly ritualized, with detailed procedures described for every conceivable event, being the accepted norm (See Vietnamica, 2012). We argue therefore, that there exists a seamless extension of such (cultural) thinking and behaviour into the lean model, which is about description in detail, of routines, operating procedures, and avoidance of deviation from the 'one best way'.

An interesting study by Yokozawa, Steenhuis and Bruijn (2010) on the two national characteristics are critical for successful kaizen transfer' mentions one as the need for 'disciplined people who follow what they are asked to do i.e. keeping the deadline, quality control, and following standard operating procedure', and the other as 'hungry mentality' which refers to 'eagerness to do the work which is above and beyond their responsibility.' We argue that both these traits link well with the dimensions of masculinity and uncertainty avoidance, discussed above, and which could be termed 'lean enabling'.

The literature reveals several cases of non Japanese nations attempting to import the lean model either being partially successful, or, being faced with several difficulties in course of their attempts to do so. Ideal examples would be the overseas affiliates of Japanese companies failing to adopt an unadulterated (pure) lean system (especially the overseas affiliates of Toyota Motor Corporation), despite trainers and executives from the parent Japanese companies locating themselves within their affiliates, to oversee the implementation of the model (ie Florida and Kenney, 1991; Abo, 1994; Liker, Fruin, and Adler, 1999). A considerable compromising of the original system was necessitated within these aforesaid contexts.

For purposes of brevity, we now discuss one such scenario selected from the literature - relating to lean adoption going wrong- namely the case of Toyota Motor Corporation (TMC) attempting to transplant its lean model (TPS) into its affiliate in India. The reason we selected this scenario, is as we feel the extent of the amenability of the Indian context to lean, at least in certain ways, corresponds with the amenability of Vietnam's context to lean.

Lean in India (The case of Toyota): Research of James (2011) reveals that those employees selected to work at Toyota's Indian affiliate (Toyota Kirloskar 
Motors -TKM), when it first came to India were overcome with a sense of euphoria. However, with time the initial excitement wore off when employees realised that the demands of Toyota's lean production model (TPS) could not be reconciled with the social frameworks they were accustomed to. The extent of inconsistency between TPS and the Indian socio-cultural milieu and worker psyche began to unravel over several years. Toyota too, on its part, seems to have underestimated the extent of compromise it would need to make to achieve a fit with the Indian environment. In the face of such problems the company was forced to re-think its entire process of doing business in India. After protracted labor unrest and a crippling strike in 2006 , and with its market share still hovering stubbornly around the 2-3\% level, the company from 2007-2008, undertook several progressive measures that seriously compromised its pure TPS philosophy. In an attempt to reconcile its approach with those of Indian cultural and societal norms, the system of TPS has now (unofficially) been transformed to TIPS (Toyota Indian Production System). Analysis of the less than impressive performance of Toyota in India, revealed major environmental / contextual variations between the Indian and Japanese scenarios, which unfolded over a period of time.

Further, research of James (2011) reveals that two of the more important socio-cultural differences that emerged as impediments to the deployment of lean by Toyota Japan into its Indian affiliate, were (i) decision making; and (ii) work ethics and motivation. These are briefly discussed below.

Decision making: The concepts of education, communication, consultation, participation, involvement, empowerment, facilitation, and support are all evident within the Japanese (Ringi) system of group-oriented, consensus-seeking decision-making, designed to integrate worker and company interests. Group work and cohesion are stressed. Responsibility is delegated to groups to perform and design tasks, identify problems, make improvements, and monitor quality. Exploring and learning together between managers, supervisors, and employees is a critical objective.

Indian companies, on the other hand (somewhat broadly similar to Vietnamese ones), prefer centralised decision making, emphasising bureaucratic and hierarchical relationships between different groups. There tends to be limited delegation and tight controls. Decisions are made by authority figures, often surrounded by strict secrecy (Jain, 1987). The common style of leadership is paternalism, invariably exhibited by superiors who are older, more experienced, and 'wiser', and is concerned with guidance, protection, nurturance, and care towards the subordinate. In return, the subordinate offers deference, loyalty, and respect to the superior.

Work ethics and motivation: The concepts of loyalty and identification with the company are stressed in Japanese systems, accompanied by devotion to one's work. However, in Indian culture, loyalty to one's family is the main priority. Employees are oriented more towards personalized relationships than productivity (Gupta, 2008). These too, are traits somewhat broadly similar to Vietnamese ones. Motivational tools in Indian companies are less oriented to increases in productivity, cost reductions, or quality improvements; rather they emphasise social, interpersonal, and even spiritual relationships with one's colleagues. Also, Indians are described as informal, emotional, sensitive, and with a lack of discipline in relation to the necessities of industrial life, in contrast 
to TPS requirements which emphasise such qualities as being punctual, precise, measured, and systematic.

Perhaps broadly explaining the inconsistencies between the Indian sociocultural milieu and the lean enabling
(Japanese) culture, are Hofstede's scores assigned to India, on dimensions of masculinity and uncertainty avoidance, (which dimensions are arguably closely linked to lean). The variance is observably quite large:

Table 1: Hofstede's Score for Japan and India

\begin{tabular}{|l|l|l|}
\hline & JAPAN & INDIA \\
\hline MASCULINITY & 95 & 56 \\
\hline UNCERTAINTY AVOIDANCE & 92 & 40 \\
\hline
\end{tabular}

(Source: The Hofstede Centre (http://geert-hofstede.com/countries.html)

The socio-cultural aspects apart, Toyota faced several other barriers in India. One example, is its attempting to deploy Just-in-Time (JIT) practices. The complexities faced by the company correspond exceedingly well with those described -in generic terms- by Linge (1991). According to this scholar, the introduction of JIT calls for not only physical changes, but also the rethinking of traditional practices, for example, the measurement of productivity and performance, and the resolution of conflicts, changes to organizational structures, which involves the managers of all departments in strategic planning and the close integration of all activities from the development of products through to their sale etc. On a wider scale, and going beyond the confines of the company, relationships between the final assembler of products and its hierarchy of primary, secondary, and tertiary subcontractors, form an essential element of the JIT approach. Also required, is a radical change in traditional attitudes within a company and among its suppliers. For example, subcontractors' ability to deliver small lots regularly and reliably several times a day may be unable to match the prices of low-cost producers which specialize in large quantities. As such JIT in Japan is a well entrenched institution across the nation, not requiring long years of effort by any one focal company, to change the mindset and work attitudes of other related companies. Does the same hold true for non Japanese environs?

\section{How congruent is Vietnam's context to lean?}

Given the similarities that appear to be present between the Indian and Vietnamese contextual factors (described at various points in the foregoing) as opposed to the Japanese / lean enabling factors, one could reason, that a good way to examine whether Vietnam's context is lean enabling, is by comparing the same with the Indian context. We do this by examining a few similarities available within factors including (i) Hofstede's scores (on Masculinity \& Uncertainty Avoidance) (ii) Decision making patterns and (iii) Work ethics and motivation.

(i) Hofstede's scores : (Masculinity \& Uncertainty Avoidance) 
Table 2: Hofstede's Score of Japan, India and Vietnam

\begin{tabular}{|l|l|l|l|}
\hline & JAPAN & VIETNAM & INDIA \\
\hline MASCULINITY & 95 & 40 & 56 \\
\hline UNCERTAINTY AVOIDANCE & 92 & 30 & 40 \\
\hline
\end{tabular}

Source: The Hofstede Centre (http://geert-hofstede.com/countries.html

The scores for Vietnam and India on both dimensions-seem closer to each other, as compared to Japan's score, with both falling in the domains of 'feminine' and 'low to medium' uncertainty avoiding cultures . The latter point is particularly of relevance (see the 'Notes' below), given that the 'one best way', a key tenet of lean, is at odds with low uncertainty avoidance index (UAI) societies. Therefore, one might argue that both societies (Vietnam/ India) are more 'lean resistant', than 'lean enabling'.

\section{Notes:}

1. Low UAI societies maintain a more relaxed attitude in which practice counts more than principles and deviance from the norm is more easily tolerated. People believe there should be no more rules than are necessary and if they are ambiguous or do not work they should be abandoned or changed. Schedules are flexible, hard work is undertaken when necessary but not for its own sake, precision and punctuality do not come naturally, innovation is not seen as threatening. Working to live, not living to work.

2. The details provided above are fully consistent with a similar study (JapaneseVietnamese cultures), available at Table 1, of the article by Nguyen;Takanash \& Aoyoma,(2012)

(ii) Decision making patterns: According to Gutterman (n.d.), employee participation in the decision making process in Vietnam was very low across all three sectors,ie State Owned Enterprises (SOEs,) Private and Joint Ventures
(JVs), with only a small percentage of the managers (mainly in the joint venture sector), indicating some tolerance for more democracy relating to how decisions are made in their organizations. Vietnamese organizations typically followed a topdown structure and employees generally accepted and supported decisions made at the top of the hierarchy without question. Supporting this line of reasoning, are Quang \& Vuong, (2002) who state that Vietnamese managers 'seldom consulted subordinates' opinions before making decision.....'

The above findings closely correspond to the scenario existing within India.

(iii)Work ethics and motivation: According to Hoang \& Dung (2009) (VN Culture \& Entrepreneurship PDF); traditional cultural values continue to have a strong impact on the Vietnamese society, and to a large extent adversely affect the entrepreneurial spirit of the community. Gutterman (n.d.) states that paternalism is a predominant feature, given the continuing importance of family values in Vietnamese culture. Managers were often involved in the family life of employees and providing social support and this was illustrated by the common practice of recruiting new employees from family members of existing workers. According to research of Quang \& Vuong, (2002) a common characteristic of the Vietnamese leadership style is that of management usually not promoting employee participation in decision making processes. Accordingly, the degree of employee 
involvement in this matter was very low. Managers in this sector were also 'less willing to provide freedom and delegation to their subordinates in deciding their course of actions. Bureaucratic, familial, conservative and authoritarian styles of management were predominant in the state sector, and also widely accepted in Vietnamese enterprises, in the private sector....such a management style has proven unsuitable for today's competitive environment'.

Whilst the above statements could be reasonably construed to mean that motivation levels are not very high, the same also seem to closely correspond with the scenario existing within India.

\section{$\underline{\text { Realities versus Optimism }}$}

According to Nguyen, Takanashi and Aoyama (2012), difficulties faced in technology transfer scenarios involving Japan-Vietnam, link with dimensions of Collectivism and Power Distance; which according to these authors could be minimized 'through strategic actions such as: managerial commitment and support, quality practice, training, team-working, frequent interaction etc, that 'have the direct impact on the behavior and mindset of local staffs and help Japanese side perceive cultural mind for at the same time..'

However, we maintain that whilst changes at the policy and structural levels etc are always possible and relatively easier to effect, the real challenge lies in changing people, their ingrained habits and mindsets, in this case from traditional Vietnamese, to traditional Japanese and vice versa, in the context of lean taking root in Vietnam. Such change takes considerable time, if it does come about. We support our argument using the ten stage model of Selfridge \& Sokolik (1975). These scholars split the overall organizational development (OD) process into ten stages, or ten targets. Whilst the Stages (targets) at levels I \& II are relatively easy for the management to tackle, as they deal with structural and policy matters, Stage $\mathrm{X}$ is where the real problems lie, given that individuals and small groups are the target of change at this stage.

\section{Discussion and Findings}

The academic literature on the transplantation of Japanese lean production and management practices into Vietnam's context is rather scant. However, the available literature and information available from several non-academic sources suggest that (i) Japanese lean management practices are increasingly being adopted by various economic sectors in Vietnam, and (ii) most of the literature, and several lean management trainers and consultants do not discuss the contextual aspects that need to be examined within Vietnam, for lean as a borrowed concept to succeed in the host nation. Whilst this qualitative study is not an empirical examination and falls more into the category of exploratory research (given the scant data available, and the focus being more on the 'what' and 'why' aspects), it attempts to highlight the critical role played by various environmental factors and the socio-cultural context of non-Japanese nations (the focus here being Vietnam) attempting to transplant the lean model on home soil. It supports the view that the efficacy of the lean model is contingent upon the similarity of a host nation's contextual factors, and such factors within Japan, out of which the lean model naturally 'emerged'. It attempts to examine the extent to which Vietnam's environmental and socio-cultural context is 'lean enabling', or otherwise.

The paper isolates from the literature the Japanese environmental and socio- 
cultural aspects that constitutes the ideal breeding grounds for lean, and attempts to link these lean enabling factors with a few dimensions of Geert Hofstede's 5-D model. Dimensions of this model that best describe the lean enabling national cultural / organizational behavior context are then compared to the Vietnamese national cultural / organizational behavior context, to check for the extent of consonance between the latter, and the ideal 'lean enabling' environment. The variation observable between Japan's and Vietnam's scores on the two chosen dimensions, are deemed as an indicative measure, of the level of success Vietnam could expect, from any lean adoption initiatives. To support this line of reasoning, a further comparison is made, between the scores and context of Vietnam and India, whose scores and context are fairly similar. The decision making and ethics and motivation patterns within these two countries are also compared, and then contrasted with the Japanese scenario. An argument is put forth, that the failure of a large Japanese firm's attempt to transplant its lean model into India, has many lessons for Vietnam, given the shared environmental/contextual traits displayed by these nations.

Our findings based on the foregoing comparative analyses, and broadly addressing the question 'How congruent is Vietnam's context to lean', suggest that:

a) The dimensions of Hofstede's national culture that seemingly are 'lean enabling, and that have a high positive influence on the lean model, are (a) masculinity and (b) uncertainty avoidance.

Japan's scores correlate very positively on these dimensions $(95,92)$, making its environment highly 'lean enabling'

b) Vietnam's scores on the above dimensions demonstrate a significantly large distance with Japan (40,30), which could logically categorize Vietnam's national culture as 'lean resistant'

c) India's scores too, on the above dimensions demonstrate a significantly large distance with Japan $(56,40)$, which also could logically categorize its national culture as being 'lean resistant'. Strongly supporting this latter point, are several cases of major Japanese MNCs failing to implement lean into the Indian context.

d) there are significant differences between how Japan addresses certain organizational processes (such as decision making and ethics and motivation), in a lean enabling manner, as compared to how the same are broadly addressed in Vietnam, which is lean resistant. However, there is strong correspondence between Vietnam's and India's approach towards these processes, with India having a poor record of effectively imbibing lean.

e) Based on the foregoing lack of correspondence between Vietnam's scores on various counts and the ideal (lean enabling ) scores on the one hand; and on the other hand, the strong correspondence between Vietnam's scores on those same counts with India's scores (and also with the Indian context being undeniably lean resistant), we could reasonably argue that there is an overall low extent of congruence that seems to exist between Vietnam's environmental-socio-cultural context, relative to the ideal context that fosters lean.

f) Flowing from the above, is our contention that a rapid, pure, or total assimilation of the lean model may not be feasible -at least in the short run - in Vietnam, and may need to be considered on a slow, cautious ,piecemeal basis, ie with a one step at a time approach .

\section{CONCLUSION}

A brief Google search on the internet 
using the words 'lean manufacturing Vietnam' and a cursory glance through the dozens of items appearing under this broad heading, provides sufficient basis for one to conclude that there is frenetic ongoing activity in Vietnam, in the direction of firms either voluntarily, or out of compulsion, adopting some or the other form of lean, particularly in the manufacturing sector.
Lean 'gurus' and consultants seem to be making a killing by hard selling their 'expertise' in all matters lean, with tall promises about 'radical transformations' that would accrue to firms adopting the model. As illustrative examples, the contents of two such campaign flyers (available in the public domain / on the internet) are shown within the box below:

a) '...2013 is the year in which Lean concepts such as strategic value, operational Kanban and several others will begin to transform entire enterprises in several industries. This will further unleash the power of the systems thinking that gained a foothold in 2013. Lean will amplify both the effects of the systems thinking already at work, and the competitive advantages of those enterprises that choose to move further down this path.

Bringing leading edge lean methods into your operations will transform your business and gain you a vital advantage over your competitors...................... You will walk away with a three day kaizen process on how to utilize Lean principles and waste elimination to deliver best quality at the lowest cost to meet customer demand. Case study results will demonstrate the validity of the strategy, model and Kaizen process..'

b) Yet another, relates to a Venture Capital (VC) firm desirous of only funding those ventures willing to adopt lean manufacturing, six sigma, etc.

Note: Shown below are the links from which the above contents have been accessed. http://www.vietnamsupplychain.com/en/event/academy-lean-manufacturing

http://leaninsider.productivitypress.com/2006/09/lean-manufacturing-in-vietnam.html

Whilst mail shots publicizing such initiatives may be well intentioned, and whilst lean does have its advantages, the question that needs asking, is whether participants of such programs are equally being made aware of 'the other side oflean' ; the fact that non-Japanese environments are often not very lean enabling; the extent of change required, to make any form of lean workable in Vietnam; and the fact that several cases exist, wherein attempts to adopt lean resulted in less than spectacular outcomes, etc.

Several studies have shown that for successful transfer of lean from Japan into unionized overseas affiliates, consideration of the contextual setting, socio-cultural environment and historical trajectories etc is critical. Research reveals that national culture continues to be a powerful force explaining a large proportion of organizational behavior. Where the aforesaid are disregarded or insufficiently addressed, efficacies of lean are sub optimal. Assumptions held regarding the transferability of the 'Lean' model as a technical object is flawed and is prone to resulting in negative outcomes. Finally, research yields that rather than a 'one best way' approach, the transplanted (Japanese lean) system -for better acceptanceneeds to be responsive and amenable to the assimilation of entrenched local (host country) socio-cultural and environmental features.

An important factor for consideration highlighted by this paper, is that unlike more traditional work systems, a successful 
adoption of the lean system involves a major change in direction, across many, or even all other organizational sub functions. Based on the foregoing, our paper suggests that it makes sense to adopt a go slow approach with toned down expectations, whilst adopting lean, or parts thereof, into Vietnam, unless management of companies adopting lean are prepared to go the full length. This leads to the question: Are they?

On a note of conclusion we cite Jean-Claude Usunier (1996, cited in Kohl, 2007), according to whom, culture could be described in terms of social representations and basic cultural orientations. While the latter only change over centuries, the former are dynamic, and tend to change within a period of ten to twenty years. It is possible to argue, that whereas the Japanese lean model is linked to Japan's basic cultural orientations, (therefore part of its national $D N A$ ), its transplanted form takes root -if it does- in overseas environments, only at the 'social representations' (i.e. cosmetic) level, and tend to come unstuck when major upheavals -like the GFC-happen to occur.

\section{REFERENCES}

Abo, T. (1994), Hybrid factory: the Japanese production system in the United States, Oxford University Press: New York

Phan Chi Anh, Zeng Jing \& Yoshiki Matsui (2011).Empirical Study on Transferability of Kaizen Practices. The 11th International DSI and the 16th APDSI Joint Meeting, Taipei, Taiwan, July 12 - 16, 2011

Berggren, C (1994), "NUMMI versus Uddevalla", Sloan Management Review, 35/2: $37-45$

Besser, T. L. (1996), Team Toyota: Transplanting the Toyota culture to the Camry plant in Kentucky, State University of New York Press: New York

Becker-Ritterspach, F (2009), Hybridization of MNE subsidiaries: the automotive sector in India, Palgrave-Macmillan: Basingstoke

Cooney, R and Sewell, G (2000), "Lean downunder: reflections on the implementation of an epoch-making model in Australia", International Workshop, University of Calabria, Rende (Italy)

Florida, R and Kenney, M (1991), "Organisation versus culture: Japanese automotive transplants in the US", Industrial Relations Journal, 22/3: 181-196

Forrester, R (1995), "Implications of lean manufacturing for human resource strategy", Work Study, 44/3: 20-24

Gough, R.,\& Fastenau, M.(2003) Implementing different concepts of lean production:

Workers' experience of lean production in North American transplants. Working Paper Series, Victoria University, School of Management.

Gupta, S (2008), "Indian and Japanese HRM practices: similarities and differences with analysis of automobile sector in India", retrieved 3 June 2009 from http://www. aimaind.org/ejournal/articlesPDF/Shruti_Gupta_692320081433269.pdf

Gutterman, A.S. (n.d) 'Vietnamese Management Systems 
Retrieved on 02 April 2013 from http://alangutterman.typepad.com/files/ mdc 05.23.2011_vietnamese-management-systems.pdf

Hofstede , G.(2011) 'The Hofstede Centre ' Retrieved on 04 April 2013 from

(http://geert-hofstede.com/countries.html)

Holsti, O.R. (1969). Content Analysis for the Social Sciences and Humanities. Reading,MA: Addison-Wesley.

Jain, H (1987), "The Japanese system of human resource management: transferability to the Indian industrial environment", Asian Survey, 27/9: 1023-1035

James, R. (2011) 'Transferring the Toyota Production System into India: Seeking Contextual Congruence'. Second Indian Academy of Management (IAM) Conference ,Indian Institute of Management( Bangalore),18th-20 th December 2011

James, R, Mathew, S, and Jones, R (2011a), "Toyota production system in India: a case study", $9^{\text {th }}$ International Academy of Business and Management Conference, Orlando, Florida.

Jean-Claude Usunier (1996, cited in Kohl, K.S. (Fall 2007).Americans doing business in Vietnam. Retrieved on 03 April 2013 from:

www.baruch.cuny.edu/wsas/student_work/documents/Kohl.pdf

Jones, R. and Liu, L (2005), “Embedding TPS within the Australian culture”, presented at the European Academy of Management, Munich

Karlsson, C. and Ahlstron, P (1996), "Assessing changes towards lean production", International Journal of Operations and Production Management, 16/2: 24-41

Krippendorff, K. (1980). Content Analysis: An Introduction to Its Methodology. Newbury Park, CA: Sage.

Liker, J and Hoseus, M. (2010), "Human resource development in Toyota culture", International Journal of Human Resources Development and Management, 10/1: $34-50$

Liker, J, Fruin, W, and Adler, P (1999), Remade in America: transplanting and transforming Japanese management systems, Oxford University Press: Oxford

Linge, G. J. (1991). “Just-in-Time: More or Less Flexible?” Economic Geography 67 (4) :316-332.

Nguyen, N., Takanashi , C., and Aoyama ,A. (2012), Can Efficient Technology Transfer Be Achieved through a Hybrid Corporate Culture? A Study on Japanese Manufacturing Subsidiaries in Vietnam

Ohno, T (1988), Toyota production system: beyond large-scale production, Productivity Press: New York

Oliver, N, Delbridge, R, and Lowe, J (1996), "Lean production practices: international comparisons in the auto components industry", British Journal of Management, Special Issue, 7: S29-S44

Pardi, T (2005), "Where did it go wrong? Hybridisation and crisis of Toyota Motor Manufacturing UK, 1989-2001”, International Sociology, 20/1: 93-118

Parker, M. and Slaughter, J (1994), "Lean production is mean production" Canadian Dimension, 28/1: 21-22 
Pil, F. K. and MacDuffie, J.P. (1999a), "What makes transplants thrive: managing the transfer of best practice at Japanese auto plants in North America ", Journal of World Business, 34/4: 372-391

Preece, D and Jones, R (2010), "Human resource development and management in lean production", International Journal of Human Resource Development and Management, 10/1: 1-13

Phan Chi Anh and Nguyen Dang Minh( 2012) Japanese Continuous Improvement Practices Implementation in Vietnamese Manufacturing Companies

International Conference : Sustainable Manufacturing and Environment Management

Quang, T and Vuong, N. (2002) "Management Styles and Organisational Effectiveness in Vietnam". Research and Practice in Human Resource Management”, 10(2), 3655.

Robbins, S (1996), Organizational behaviour, Englewoods Cliffs, NJ

Schutt, R. K.,(2006) Investigating the Social World, 5th ed, Pine Forge Press

Selfridge, R., Sokolik, S. (1975) “A comprehensive view of organizational management”. MSU Business Topics, 23(1), 46-61

Sugimore, Y, Kusunoki, K, Cho, F, and Uchikawa, S (1977), “Toyota production system and kanban system: materialisation of just-in-time and respect-for-human system", International Journal of Production Research, 15/6: 553-564

Vietnamica (2012).Retrieved on 01 April 2013 from :

www.vietnamica.net/vietnams-national-culture-scores-by-geert-hofstede

Wertz, F J, Charmaz, K, McMullen, L M, Josselson, R, Anderson, R, and McSpadden, E (2011), Five ways of doing qualitative analysis, Guildford Press: New York.

Westney, D (1999), "Organization theory perspectives on the cross-border transfer of organizational patterns", in Liker, J, Fruin, W, and Adler, P (eds), Remade in America: transplanting and transforming Japanese management systems, Oxford University Press: New York, 385-408

Wilms, W, Hardcastle, A. J, and Zell, D.M (1994), "Cultural transformation at NUMMI”, Sloan Management Review, 36/1: 99-113

Womack, J. P, Jones, D. T, and Roos, D (1990), The machine that changed the world, Macmillan: New York

Womack, J P and Jones, D T (1996), Lean thinking: banish waste and create wealth in your corporation, Simon and Schuster: New York

Worley, J. M. and Doolen, T.L (2006), "The role of communication and management support in a lean manufacturing implementation", Management Decision, 44/2: 228-245

Yokozawa, K, Steenhuis, H, and de Bruijn, E. J (2010), The influence of national culture on Kaizen transfer: An exploratory study of Japanese subsidiaries in the Netherlands, paper presented at the 15th Cambridge International Manufacturing Symposium, Cambridge, UK. 